\title{
Effects of hydropower construction on spatial-temporal change of land use and landscape pattern. A Case Study of Jinghong, Yunnan, China
}

\author{
Shiyi Jiang ${ }^{1, a}$, Heping Zeng ${ }^{1, b^{*}}$, Minxia Cao ${ }^{1, c}$, Zhantai Wang ${ }^{1, d}$ and Huiqun \\ Huang ${ }^{1, f}$
}

${ }^{1}$ Kunming University of Science and Technology, Faculty of Environmental Science and Engineering, 650500 Kunming, Yunnan, China

ajiangshiyi111@163.com, 'dabatou@126.com, ${ }^{c} 15887849873 @ 163 . c o m$, d18468088535@163.com, 'huanghuiqun1014@sina.com

Keywords: hydropower; land-use; landscape pattern; Jinghong

Abstract. Selecting Jinghong hydropower station as a study case, we studied the spatial-temporal change of land use and landscape pattern during 2004,2009 and 2013 based on the application of RS interpretation, ArcGIS 10.1 analysis and Fragstats3.4. The results showed that: 1) Area of tea garden, traffic land, residential land, bare land, hot shrub grass and rubber plantation was a growing trend. Area of dry land, beach, tropical seasonal rainforest, tropical montane rain forest, paddy land, water and banana was a declining trend. The residential land and dry has maximum increment and maximum decrement, which annual changes percentage and increment was $5.11 \%, 1182.22 \mathrm{hm}^{2}$ and $2.37 \%$, $838.86 \mathrm{hm}^{2}$, respectively; 2) the landscape matrix showed a trend of fragmentation and discrete distribution, and the shape of patches became more complex. The fragmentation, aggregation, heterogeneity and diversity showed decreasing firstly and then increasing trend in the whole.

\section{Introduction}

In 1995, International Geosphere-Biosphere Program (IGBP) and International Human Dimension Program on Global Environmental Change (IHDP) put forward "land use and land cover changes (LUCC) of science research plan", which push LUCC has become the core content of the global change[1,2,3]. It can bring the huge changes of the landscape structure and affect the material circulation and energy flow of the landscape, and also has a profound impact on the region biological diversity, important ecological processes and sustainable utilization of resources and environment[4,5,6]. LUCC is the result of complex natural environmental and human social factors[7,8]. Changes of land use pattern is basic of LUCC[9]. In-depth analysis of land use change is basic of understanding of land use and land cover change rule, prediction of the future trend of land use change and foundation of the sustainable land use decisions[10].

Land use changes affect the landscape of the surface and landscape change is the most intuitive sign of land use change[11,12]. Nowadays, the landscape pattern analysis method has been widely introduced into the research of land use change[13,14]. Because the hydropower resources are very rich in the western regions of China, more and more hydropower stations or dams will be built in here. Hydropower development not only bring huge economic, social and ecological benefits, but also inevitably change the regional land use situation and reconstruct the landscape framework[15,16]. The exploitation of the Lancang River basin in Yunnan for hydropower development commenced 60 years ago. Since the 1980s, Lancang hydropower development has taken place on the mainstream with a cascade development of eight dams planned. Jinghong hydropower station is one of the six cascade dams which started in 2002. Jinghong dam is about $5 \mathrm{~km}$ from Jinghong city. Dam construction is a serious impact on the land use and landscape pattern in Jinghong city. In this study, based on the three periods of remote sensing images in 2004, 2009 and 2013 with the software platform of GIS, ERDAS and Fragstats, we analyzed the spatial-temporal changes of land use and landscape pattern. 


\section{Materials and methods}

Study area. Jinghong hydropower station is the first large-scale main stream hydropower station in Lancang River which is located in northern suburbs in Sipsongpanna city, Yunnan(Fig. 1). This hydropower station is based on power generation and has the comprehensive utilization benefit of shipping, flood control, tourism. Jinghong hydropower station construction began in 2002 and started to put into use in 2008 . The reservoir capacity and regulating capacity is $11.4 \times 10^{6} \mathrm{~m}^{3}, 3.09 \times 10^{6} \mathrm{~m}^{3}$, respectively. The dam is $704.5 \mathrm{~m}$ long and $108 \mathrm{~m}$ high. It installs 5 mixed-flow style turbine-generator units with unit capacity of $350 \mathrm{MW}$ and has a total installed capacity of $1759 \mathrm{MW}$ and the security of the 771.9 MW. The average annual energy output, utilization hours of installed capacity, rainfall, stream-flow, runoff, sediment concentration and temperature is $78.58 \times 10^{6} \mathrm{~kW} . \mathrm{h}, 4409 \mathrm{~h}, 1161.2 \mathrm{~mm}$, $1820 \mathrm{~m}^{3} / \mathrm{s}, 574 \times 10^{6} \mathrm{~m}^{3}, 1.82 \mathrm{~kg} / \mathrm{m}^{3}$, and $22^{\circ} \mathrm{C}$ in dam site for many years, respectively[17].

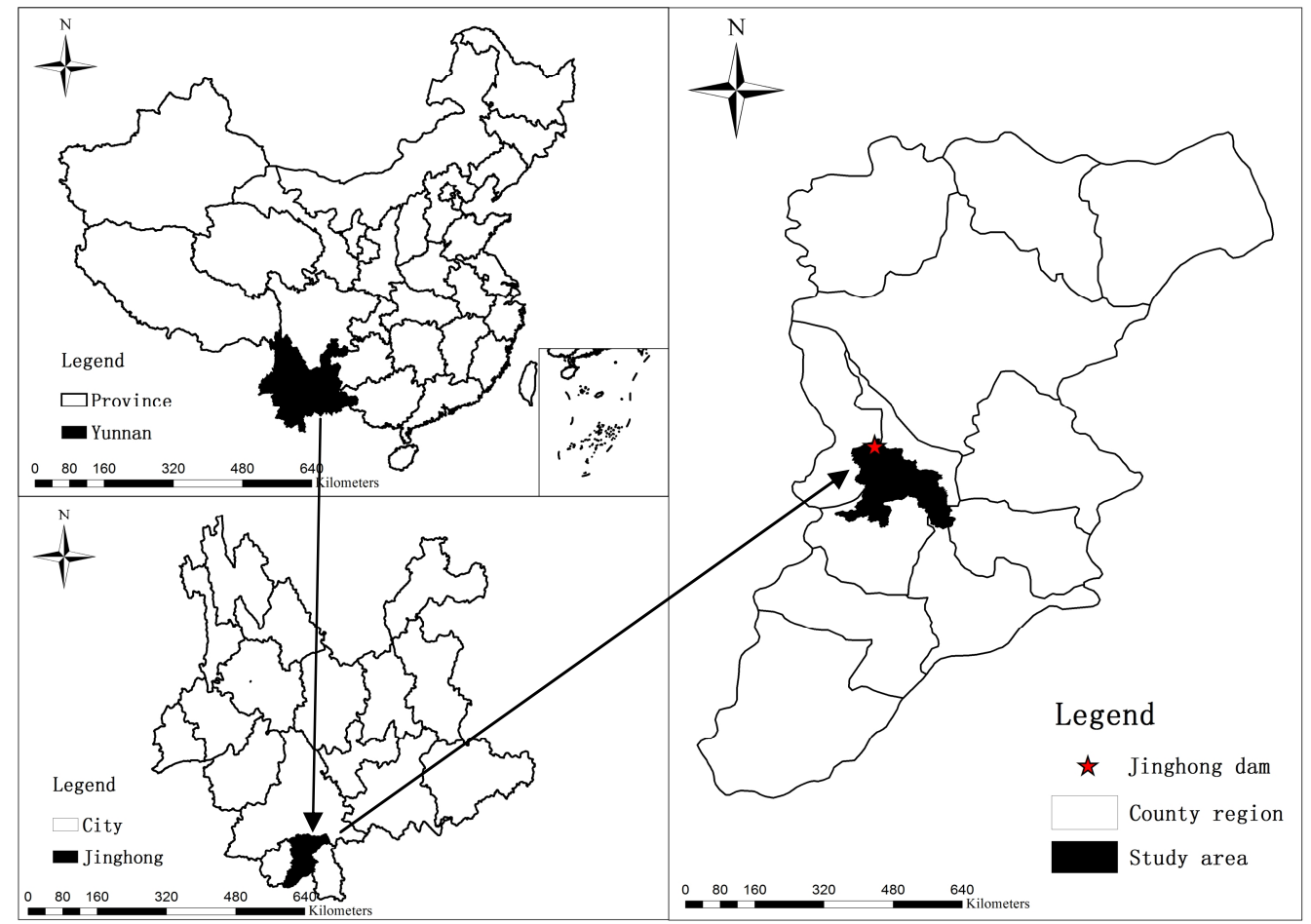

Fig. 1 Location of the study area

Data sources and description. Remote sensing images used in this study are derived from the image data acquired by Landsat 7 ETM SLC-off and Landsat 8 OLI_TIRS for the NASA. The study selected Landsat 7-ETM ${ }^{+}$in December, 2004, April and November, 2009, Landsat 8-OLI in June, 2013 as the main remote sensing data sources to reflect the spatial data of land use in different periods hydropower stations construction. The resolution of these three images were $30 \mathrm{~m} \mathrm{x} \mathrm{30m.} \mathrm{We} \mathrm{used} \mathrm{the} \mathrm{geometric}$ correction of ERDAS 9.2 to geometrically correct and extracted the geographical information first, and then cut and mosaic images. Finally, combined visual interpretation and automatic classification method, the classify images of land use were made. According to present situations of land use and current land use condition classification criteria (GB/T21010-2007), the classified classes were water, residential land, banana, rubber plantation, hot shrub grass, tropical seasonal rainforest, tropical montane rain forest, dry, bare and traffic land, beach, tea garden and paddy field. Actually, these land-use maps were made and modified in ArcGIS 10.1 with 97\% accuracy, and it is based on field investigations and Google Earth software (Fig. 2). 

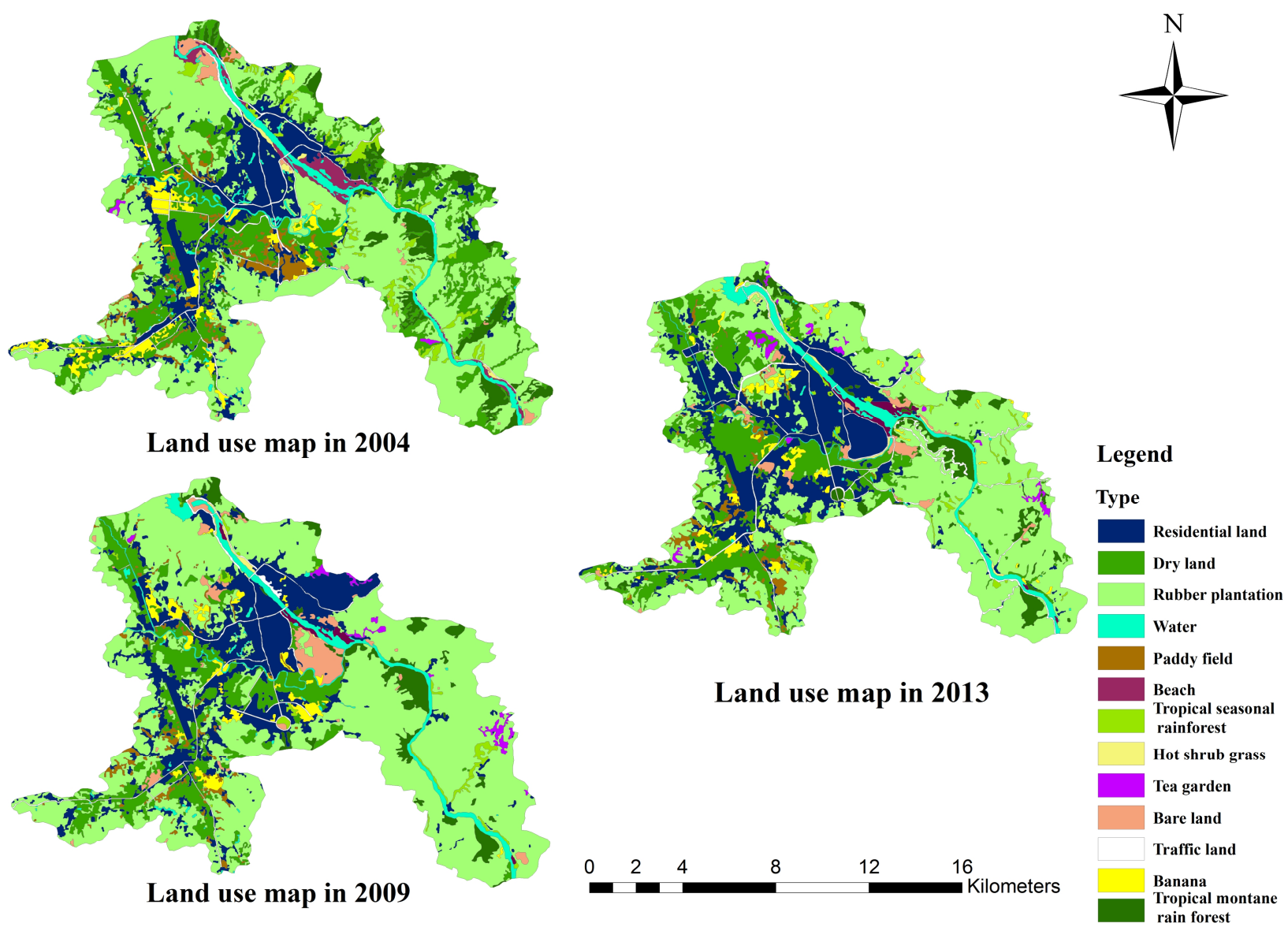

Fig. 2 Distribution of land-use types in different years

Dynamic change of land use. The process and trends of land use changes can be represented by amplitude of variation, area variance ratio, spatial change speed, regional change trend index and so on[18]. In General, a single landscape dynamic degree is used to indicate area changes of a specific landscape type in a certain period of time. It can quantitatively describe the rate of regional land use change, be expressed as Eq. 1[19]:

$$
K=\frac{U_{b}-U_{a}}{U_{a}} \times \frac{1}{T} \times 100 \%
$$

Where $K$ is the annual change rate of a specific landscape type during the study period; $T$ is the study period; $U_{a}$ and $U_{b}$ represent areas of a specific landscape type at the beginning and end of the study.

Selection landscape index. Landscape is a region with high spatial heterogeneity, which is composed of many different sizes and shapes of patches according to certain rules. The spatial distribution of patches is called landscape pattern[20]. Patch is the basic unit of landscape. Changes of quantity, area and structure of patches reflect the landscape pattern of a region. Based on Fragstats3.4, selected landscape pattern indices has the following several: NP, PD, SHDI, LPI and AI in this study (Table 1).

Table 1 List of the selected landscape pattern indices in study area

\begin{tabular}{|c|c|c|}
\hline Abbreviation & Index name & Description \\
\hline $\mathrm{PD}$ & Patch density & Reflect landscape fragmentation of a type in the \\
\hline LPI & Largest patch index & landscape. \\
\hline AI & Aggregation Index & Reflect the degree of aggregation of a patch type. \\
\hline SHDI & $\begin{array}{l}\text { Shannon's diversity } \\
\text { index }\end{array}$ & $\begin{array}{l}\text { Reflect the heterogeneity of landscape, emphasizes the } \\
\text { contribution of patch types to information. }\end{array}$ \\
\hline NP & Number of Patch & $\begin{array}{l}\text { Reflect the spatial pattern of landscape and used to } \\
\text { describe the heterogeneity of the whole landscape. }\end{array}$ \\
\hline
\end{tabular}




\section{Result}

Dynamics of single land-use change. Land use change of all types is shown in Fig. 3. The results show as follows: area of tea garden, traffic land, residential land, bare land, hot shrub grass and rubber plantation was a rising trend during 2004-2013 period. Area of the residential land increased significantly by $1181.62 \mathrm{hm}^{2}$, which annual changes percentage was $5.11 \%$; Followed by area of rubber plantation, tea garden and traffic land was increased slightly by $221.88 \mathrm{hm}^{2}, 149.22 \mathrm{hm}^{2}$ and $107.3 \mathrm{hm}^{2}$, respectively. Their annual changes percentage reached $0.28 \%, 59.4 \%$ and $2.05 \%$, respectively. However, area of the remaining seven land-use types were a declining trend in 9 years. Annual changes percentage of beach was the largest because of dam construction actuating other land use types transformed to it. The maximum annual decrement was dry reached $838.86 \mathrm{hm}^{2}$, which the reduced rate was $2.37 \%$. The minimum reduced rate was $0.13 \%$ for water due to river closure of dam construction.

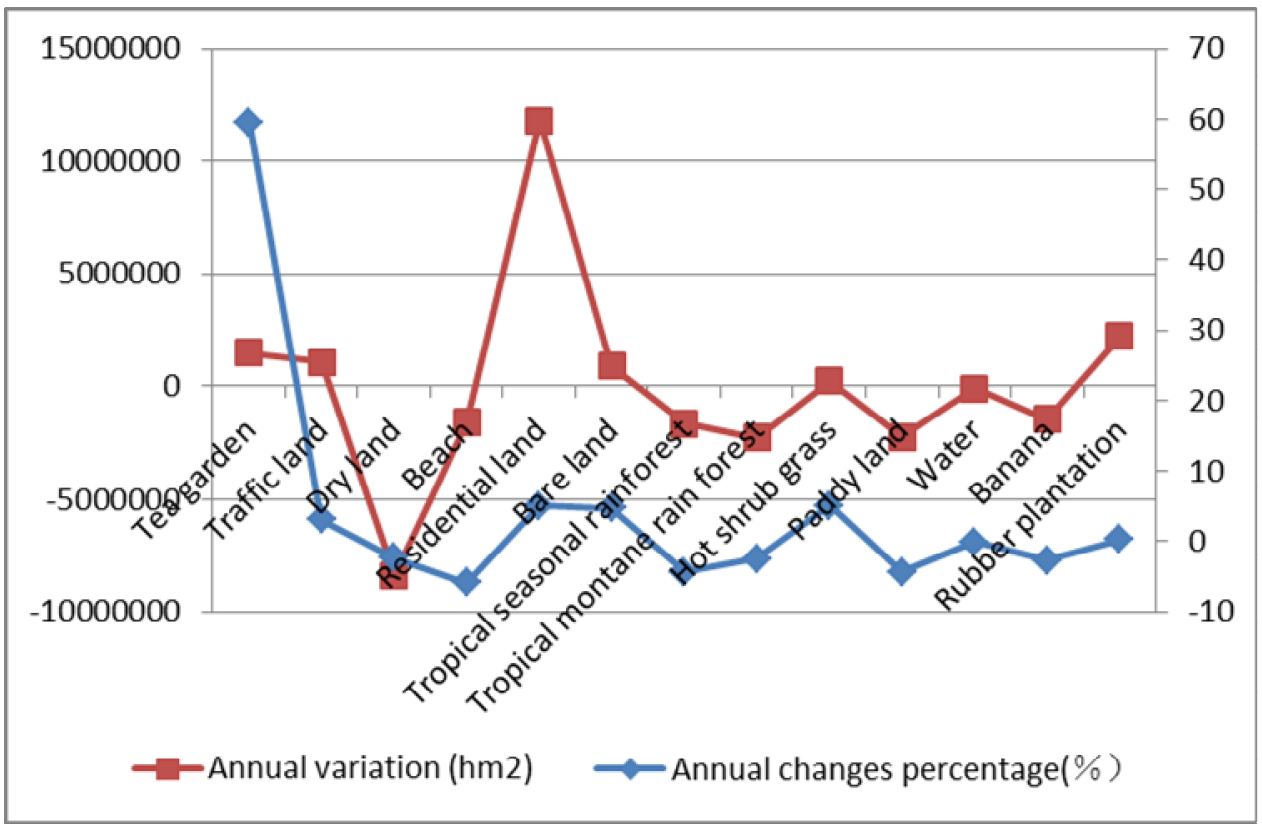

Fig. 3 Dynamic changes of single land-use type from 2004 to 2013

Analysis of characteristics of landscape pattern in landscape level. The characteristics of pattern is the result of the interaction of all kinds of landscape types in landscape level. According to the results of Fragstats 3.4 calculation, it indicates that landscape structure of Jinghong city has changed significantly during 2004-2013 period. PD and LPI reflect dominance of landscape. Their more higher value indicate the proportion of different landscape types exist bigger difference and one or several land-use types are to be in the ascendant. As shown in the table 2, PD and LPI value were first decreased and then increased that indicated landscape structure of Jinghong may be influenced by human activity or local policy the pre- and post-dam periods. AI reflects degree of aggregation and dispersion of patches of a landscape type. This research shown an upward trend for AI value from 88.5535 to 91.5117 during 2009-2013 period. This may be because of re-planning of the city during the construction of the dam. However, AI value existed a slightly upward from 91.5117 to 89.9138 . This indicated that patches of landscape types were gradually dispersed during four years. SHDI is comprehensive reflection of landscape richness and combinatorial complexity and determined by the number of landscape types and the proportion of all patches of types. Namely, SHDI value is more higher and area ratio distribution is more uniform. As shown in the table 2, SHDI has decreased from 1.739 to 1.6941. This change was explained the land use of Jinghong city may be influenced by human activity, such as residential land and tropical montane rain forest are largely converted to rubber plantation for the increasing personal income. NP reflects complexity degree of patches and has highly positive correlation with the fragmentation. NP value were first decreased and then increased. This trend was largely due to the strong interference of human activities on land use. 
Table 2 Landscape pattern index at landscape level from 2004 to 2013

\begin{tabular}{cccccc}
\hline Year & PD & LPI & AI & SHDI & NP \\
\hline 2004 & 5.0671 & 6.7648 & 88.5535 & 1.739 & 1518 \\
2009 & 3.4208 & 16.642 & 91.5117 & 1.5423 & 1125 \\
2013 & 4.1649 & 14.9873 & 89.9138 & 1.6941 & 1375 \\
\hline
\end{tabular}

“.": SHDI has no unit.

Transfer area matrix of land use types. The land use transfer matrix can be used to describe the change of landscape types in the study area. It can not only reflect landscape structure of the initial and last stage of the study area, but also reflect the source and future development trend of all kinds of landscape. In this study, all kinds of landscape have different degrees of transformation from 2004 to 2013 (Table 3). As shown in the table 3, the total of area of tea garden, traffic land, residential land, bare land, hot shrub grass and rubber plantation were increased, and the total area of dry land, flood land, tropical seasonal rain forest, tropical montane rain forest, paddy field and water were decreased. The maximum area of growth was residential land. It was increased by $1181.62 \mathrm{hm}^{2}$ and increment rate was $46 \%$. The largest transfer area of landscape types were dry land and rubber plantation and the contribution rates were $31.27 \%$ and $33.67 \%$, respectively. The least transfer area of type was tea garden with the transfer area was $3.14 \mathrm{hm}^{2}$. Otherwise, the minimum area of growth was hot shrub grass, its increment was $22.42 \mathrm{hm}^{2}$ and increment rate was $45.83 \%$. Its largest transfer area of type was water and the contribution rate was $27.5 \%$; tea garden and banana had no conversion to hot shrub grass due to location and climatic conditions of it. On the other hand, the maximum area of decreased was dry land. It was decreased by $838.86 \mathrm{hm}^{2}$ and its reduced rate was $21.26 \%$. The transfer area of dry land was $2795.13 \mathrm{hm}^{2}$. The contribution of residential land and rubber plantation were more larger than other types, reached $22.77 \%$ and $56.04 \%$, respectively. Conversely, the minimum area of growth was water, its decrement was $9.07 \mathrm{hm}^{2}$ and decrement rate was $1.24 \%$. The transfer area of water was $289.09 \mathrm{hm}^{2}$. The contribution of residential land, dry land and rubber plantation were largest reached $33.97 \%, 15.56 \%$ and $15.08 \%$

Table 3 Change matrix of land-use landscape types in this study $\left(\mathrm{hm}^{2}\right)$

\begin{tabular}{|c|c|c|c|c|c|c|c|c|c|c|c|c|c|c|}
\hline \multirow[b]{2}{*}{2004} & \multicolumn{13}{|c|}{2013} & \multirow[b]{2}{*}{ Total } \\
\hline & $\begin{array}{c}\text { Tea } \\
\text { garden }\end{array}$ & $\begin{array}{l}\text { Traffic } \\
\text { land }\end{array}$ & $\begin{array}{l}\text { Dry } \\
\text { land }\end{array}$ & Beach & $\begin{array}{l}\text { Residential } \\
\text { land }\end{array}$ & $\begin{array}{l}\text { Bare } \\
\text { land }\end{array}$ & $\begin{array}{l}\text { Tropical } \\
\text { seasonal } \\
\text { rainforest }\end{array}$ & $\begin{array}{l}\text { Tropical } \\
\text { montane } \\
\text { rain forest }\end{array}$ & $\begin{array}{l}\text { Hot } \\
\text { shrub } \\
\text { grass }\end{array}$ & $\begin{array}{l}\text { Paddy } \\
\text { land }\end{array}$ & Water & $\begin{array}{c}\text { Banan } \\
\text { a }\end{array}$ & $\begin{array}{l}\text { Rubber } \\
\text { plantation }\end{array}$ & \\
\hline Tea garden & & & 3.01 & & 3.14 & & & & & 2.55 & 0.4 & & 18.8 & 27.91 \\
\hline Traffic land & 0.32 & 75.08 & 85.67 & 4.45 & 131.88 & 4.07 & 4.65 & 5.62 & 10.3 & 1.8 & 24.02 & 15.46 & 27.13 & 390.46 \\
\hline Dry land & 28.08 & 76.91 & 1151.1 & 5.74 & 637.01 & 77.21 & 28.73 & 69.7 & 4.7 & 85.94 & 28.66 & 185.97 & 1566.48 & 3946.23 \\
\hline Beach & & 11.43 & 9.51 & 74.75 & 66.36 & 2.23 & 8.04 & 11.76 & 9.28 & & 104.7 & 1.29 & 9.18 & 308.52 \\
\hline Residential land & 5.49 & 67.81 & 200.86 & 3.28 & 1714.48 & 21.5 & 24.52 & 23.49 & 5.09 & 51.64 & 11.27 & 57.43 & 383.22 & 2570.1 \\
\hline Bare land & 0.03 & 18.5 & 11.93 & & 25.48 & 1.94 & 2.51 & 22.41 & 9.18 & 3.26 & 16.86 & 7.94 & 91.19 & 211.23 \\
\hline $\begin{array}{l}\text { Tropical seasonal } \\
\text { rainforest }\end{array}$ & 0.02 & 16.62 & 30.38 & & 33.84 & 7.29 & 4.14 & 16.77 & 2.16 & & 3.69 & 3.91 & 296.18 & 415.01 \\
\hline $\begin{array}{l}\text { Tropicalmontane } \\
\text { rain forest }\end{array}$ & 5.32 & 32.87 & 4.86 & 4.74 & 12.41 & 29.57 & 8.23 & 376.09 & 0.43 & & 8.8 & 9.16 & 544.06 & 1036.53 \\
\hline Hot shrub grass & & 0.31 & 0.41 & 0.44 & 19.34 & & 10.67 & 8.94 & & & 7.21 & 1.49 & 0.11 & 48.92 \\
\hline Paddy land & 1.08 & 19.03 & 139.08 & & 201.04 & 13.01 & 0.06 & 22.72 & 0.18 & 74.83 & 2.95 & 36.31 & 60.08 & 570.37 \\
\hline Water & & 10.4 & 44.97 & 19.1 & 98.21 & 8.96 & 6.86 & 8.86 & 19.62 & 27.13 & 444 & 1.39 & 43.59 & 733.05 \\
\hline Banana & 5.22 & 19.18 & 338.32 & & 122.59 & 10.29 & & & & 6.04 & 4.55 & 18.89 & 67.26 & 592.35 \\
\hline Rubberplantation & 131.56 & 149.62 & 1087.3 & 32.72 & 685.95 & 125.18 & 152.43 & 242.94 & 10.41 & 94.63 & 66.9 & 105.81 & 5758.57 & 8643.99 \\
\hline Total & 177.13 & 497.77 & 3107.4 & 145.2 & 3751.72 & 301.26 & 250.83 & 809.29 & 71.34 & 347.8 & 724 & 445.06 & 8865.87 & 19494.7 \\
\hline
\end{tabular}




\section{Discussion and Conclusion}

Dam construction can bring huge economic benefits, such as power generation, irrigation, shipping and so on, to promote the development of the national economy. Meanwhile, it inevitably cause a series of influence to the stability of ecosystem, the situation of soil erosion, land use and landscape pattern. Hydropower station construction will cause different degrees of impact and risk to the ecological security of the river basin[18,21,22]. In this study, we use the method of landscape ecology to analyze spatial-temporal change of the land use and landscape pattern of Jinghong city before and after the establishment of Jinghong hydropower station, which is supported by remote sensing and GIS technology.

The results showed that: from 2004 to 2009, land use and landscape pattern of Jinghong city has been seriously change due to be affected by human activities during the dam construction period. The proportion of different landscape types exist bigger difference and one or several land-use types are to be in the ascendant. The landscape diversity has a slight decline from 1.739 to 1.5432 , due to re-planning of land use for dam construction. From 2009 to 2013, land use and landscape pattern of Jinghong city was influenced by human activities and local policies during the operation of the hydropower station. In particular, the construction of the dam further increased the damage to the overall landscape pattern[23]. The landscape matrix showed a trend of fragmentation and discrete distribution, and the shape of patches became more complex. The landscape diversity has a slight rise from 1.5423 to1.6941. Meanwhile, it existed mutual transformation between different landscape types. The maximum and minimum area of increased were residential land and hot shrub grass, which reached $1181.62 \mathrm{hm}^{2}$ and $22.42 \mathrm{hm}^{2}$, respectively. Otherwise, the maximum and minimum area of reduced were dry land and water, which reached $838.86 \mathrm{hm}^{2}$ and $9.07 \mathrm{hm}^{2}$, respectively. In addition, the information derived from this study can have direct application values to state and local agencies, city planners and government resource managers for land use planning of the city.

\section{Acknowledgements}

This research was financially supported by the National Natural Science Foundation of China (NSFC) (41461061).

\section{References}

[1] Scientific Steering Committee and International Project Office of LUCC, C. Nunes, J.I. Augé, Land-Use and Land-Cover Change (LUCC): Implementation Strategy, Environ. Policy Collect. 1999.

[2] B.L.I. Turner, D.L. Skole, S. Sanderson, G. Fischer, L. Fresco, R. Leemans, Land-use and land-cover change. science/research plan, Global Change Rep.. 43 (1995) 669-679.

[3] S.M. Sterling, A. Ducharne, J. Polcher, The impact of global land-cover change on the terrestrial water cycle, Nat. Clm. Change. 3 (2013) 385-390.

[4] L. Claessens, J.M. Schoorl, P.H. Verburg, L. Geraedts, A. Veldkamp, Modelling interactions and feedback mechanisms between land use change and landscape processes, Agr. Ecosyst. Environ.. 129 (2009) 157-170.

[5] H.Q Tian, G. Chen, C. Zhang, M.L. Liu, G. Sun, A. Chappelka, W. Ren, X.F Xu, C.Q. Lu, S.F. Pan, H. Chen, D.F. Hui, S. McNulty, G. Lockaby, E.Vance, Century-scale response of ecosystem carbon storage to multifactorial global change in the Southern United States. Ecosystems. 15 (2012) 674-694.

[6] P. Meyfroidt, E.F. Lambin, K.H. Erb, T.W. Hertel, Globalization of land use: distant drivers of land change and geographic displacement of land use. Curr. Opin. Env. Sus.. 5 (2013) 438-444. 
[7] E.F. Lambin, H.J. Geist, E. Lepers, Dynamics of land-use and land-cover change in tropical regions, Annu. Rev. Env. Resour.. 28 (2003) 205-241.

[8] L.Y. Zeng, S.Q. Wei, LUCC Ecological Security Analysis of Fuzhou Based on Landscape Pattern, Journal of Fujian Normal University (Natural Science Edition). 4 (2011) 029. ( in Chinese )

[9] A. Veldkamp, E.F. Lambin. Predicting land-use change, Agr. Ecosyst. Environ.. 85 (2001) 1-6.

[10] Q. Zhou, Z. Zhang, X.K. Ou, Multivariable analysis of socio-economic factors to drive the land-use changes in the area of Manwan Dam, Acta Ecologica Sinica. 30 ( 2010) 165-173. ( in Chinese )

[11] X. Cui, L. Zhang, L. Zhu, G. Song, B. Wu, Changes of landscape pattern and its characteristics in Kaixian county before and after impoundment of Three Gorges Dam Project, Transactions of the Chinese Society of Agricultural Engineering. 28 (2012) 227-234(8). ( in Chinese )

[12] Y. Feng, G. Luo, L. Lu, D. Zhou, Q. Han, W.Q. Xu, C.Y. Yin, L. Zhu, L. Dai, Effects of land use change on landscape pattern of the Manas River watershed in Xinjiang, China, Environ. Earth Sci.. 64 (2011) 2067-2077.

[13] W. Hao, W. Wang, W. Wang, J.X. Qin, X. Bai, Research on the Characteristics of Landscape Pattern and Change in Changsha-Zhuzhou-Xiangtan Metropolitan Region, Journal of Geo-Information Science. 12 (2010) 133-142. ( in Chinese )

[14] Y.T. Yang, J.Y. Gong, Q.M. Zhou, Y.Y. Wang, Impacts of Landscape Pattern on Urban Expansion:A Case Study of Beijing City, Journal of Natural Resources. 25 (2010) 320-329. ( in Chinese )

[15] P. Rautela, R. Rakshit, V.K. Jha, R.K. Gupta, A. Munshi, GIS and remote sensing-based study of the reservoir-induced land-use/land-cover changes in the catchment of Tehri dam in Garhwal Himalaya, Uttaranchal (India), Curr. Sci. India. 83 (2002) 308-311.

[16] Z. Guo, X. Xiao, Y. Gan, Y Zheng, Landscape planning for a rural ecosystem: case study of a resettlement area for residents from land submerged by the Three Gorges Reservoir, China, Landscape Ecol.. 18 (2003) 503-512.

[17] J.T. Liu, Hydropower Development on Lancang River and Design of the Jinghong Hydropower Station, Water power. 34 (2008) 28-31. ( in Chinese )

[18] Q. Zhao, S. Liu, S. Dong, Effect of Dam Construction on Spatial-Temporal Change of Land Use: A Case Study of Manwan, Lancang River, Yunnan, China, Procedia Environ. Sci.. 2 (2010) 852-858.

[19] J.H. Pan, S.Y. Cai, Y.S Huang, X. Liu, Land use \& landscape pattern change and its driving forces in Yumen City, Geographical Research. 31 (2012) 1631-1639. ( in Chinese )

[20] D.N. Xiao, J.X. Li, J. Gao, T.S. Li, Landscape Ecology, Science Press, Beijing, 2003, pp31-52. ( in Chinese )

[21] R. Sternberg, Damming the river: a changing perspective on altering nature, Renew. Sust. Energ Rev.. 10 (2006) 165-197.

[22] W. Ouyang, A.K. Skidmore, F. Hao, A.G., A. Abkar, Toxopeus Accumulated effects on landscape pattern by hydroelectric cascade exploitation in the Yellow River basin from 1977 to 2006, Landsc. Urban Plan.. 93 (2009) 163-171.

[23] Q. Zhao, S. Liu, Z. Zhang, L. Deng, Effects of Manwan hydropower exploitation on dynamic changes of landscape pattern in related reservoir area, Chinese Journal of Ecology, 30 (2011) 2343-2350. ( in Chinese ) 